\title{
A Study of Negative Language Transfer in College Students' Writing from Cultural Perspective
}

\author{
Lin Bai \\ Shanxi Normal University, Linfen, China \\ Jie Qin \\ School of Foreign Languages, Shanxi Normal University, Linfen, China
}

\begin{abstract}
Language and culture are closely related with each other and they are inseparable. Language, as a vehicle of culture, is as well culture's manifestation. Transfer, as an important notion in Second Language Acquisition (SLA), states the situation of previously existing knowledge being extended and expanded to the gaining of new knowledge. Language transfer can be classified into positive, negative and zero transfer. As for the definition of positive transfer, it is the transfer that helps or facilitates language learning in another situation. Negative transfer is one that interferes with language learning in another situation. How to utilize the positive transfer and avoid negative transfer is of great significance in Foreign Language Teaching (FLT). Aiming to improve college students' English writing, the author tries to analyze the negative transfer from the cultural perspective. With the guidance of the theory of Language Transfer, the author carries out a research on the students' writing tasks. Based on the research, author has discovered the interference of their mother tongue in students' writings shown in idioms, cultural terms and conventions in expression. Therefore, the students are not free to use language to explain their arguments. The study also found these negative transfer are mostly generated by cultural difference. The sources of negative transfer include in the three aspects which are thinking mode, aesthetic perception and religious belief. Thus students should find some solutions and avoid negative transfer efficiently.
\end{abstract}

Index Terms—negative language transfer, culture, college students' writing

\section{INTRODUCTION}

With the economic development and globalization, the whole world is now called the global village. In the process of globalization, different cultures are blended together. What is more, culture blending has become a major trend in the development of today's world. In order to understand another nation's culture, we need to know its language first. The ultimate goal for foreign language learning is to communicate, especially to communicate interculturally. Owing to the huge difference among language, culture background and living habits, it is absolute for two people who are from distinct countries to make mistakes in understanding, or even get angry on some specific occasions. Thus for the sake of successful communication, the crucial point is to start to treat another nation's tradition and habits objectively after acquiring another culture and its thinking patterns carefully.

Despite the fact that English teaching in China has been developed prosperously and vigorously, it is still far from satisfactory, especially in terms of speaking and writing skills. Because of the intimate relationship between language and culture, Chinese English learners inevitably transfer its native traditions, values or thinking patterns into their English learning process. As a result, Chinese students are good at writing English compositions in English words but in Chinese thinking mode.

Therefore studying on this subject will be of great significance from both students' and teachers' aspect. Chinese English learners tend to write their compositions under the guidance of their native culture. Sometimes although there are few mistakes in their compositions, they still seem to be more or less odd when reading by native speakers. One of the main reasons is that the learners are not familiar with target culture, which will result in misunderstanding. Therefore, detecting the negative transfer of native culture and offering solutions will become an effective way to improve both our teachers' and the students' writing proficiency.

\section{LITERATURE REVIEW}

\section{A. Theoretical Basis}

\section{Language transfer}

Within the field of applied linguistics, researchers and scholars are likely to define a term under their own steams. The definition of the term transfer is one among these terms. Odlin (2001) argued transfer is not simply a consequence 
of habit formation. This discussion is quite different from the view of behaviorists (which will be explained in the following subchapter). They propose that language acquisition simply a "habit-formation" process. To put it simple, they see language acquisition as a process to overcome the "old habit," and to form a "new habit." "Transfer" is originally one of the basic terms appeared in the domain of psychology. Under the context of psychology, it states the situation of previously existing knowledge being extended and expanded to the process of gaining new knowledge, i.e. the influences that the process of acquiring and memorizing one thing occurred upon acquiring and memorizing of other things (Sajavaara, 1986). It is exactly this concept that forms the psychological basis for "language transfer." Sharwood Smith as well as Eric Kellerman in 1986, for example, held that the term of transfer should be narrowed and restricted to the phenomenon which results in the incorporation of the same elements existing from a certain language into others.

2. The concept of culture

According to what Lado recorded in 1957 in his book Linguistics across Cultures: Applied Linguistics for Language teachers, maybe Kluckhohn and Kelly are those who illustrated this modern concept the best for they consider the term culture as all the created ones at any given time in history aiming for human beings to behave themselves decently under the guidance of those displayed either implicitly or explicitly, rationally, irrationally, or even non-rationally.

In 1959 Kluckhohn expressed in his book Mirror for Man that cultures are learned by individuals since different groups possess their own cultures; besides, culture contains those learned behaviors and performances shared among insiders. Contrary to biological inheritance, culture belongs to our social heritage which is a paramount element in making enormous amount of people to live harmoniously in organized societies, providing us with pre-existing solutions to consult to in terms of encountered problems, helping us to judge and even predict others' intentions under their behaviors, and allowing others to tell our expectations.

3. Contrastive analysis hypothesis $(\mathrm{CAH})$

In the 1940s and 1960s, the theory of language transfer was dominant in the research and teaching of L2 acquisition. Linguists regarded language transfer as the major obstacles of L2 acquisition and believed that the learners' errors and difficulties could be predicted through the contrast of native and target languages. Contrastive Analysis Hypothesis (CAH), systematically comparing two languages, was most popular at that time. Being propelled by the possibility of distinguishing similarities and differences existing between the target language and the native language, Contemporary researchers are devoting themselves into generating a relatively more effective teaching method. Many researches still call for the need of contrasting the native language and the target language, such as Eckman (1977), James (1980) and Ellis (1994).

\section{Error analysis (EA)}

Error Analysis (EA) is the analytical method aiming to analyze errors made by those learners who attempt to acquisition a second or foreign language. Based on what Richards (2000) said, error analysis is employed so as to check to what extent a person knows about a language, the way a person used in his or her learning language processes, and find out learners' common difficulties revealed in their language learning courses in order to better optimize teachers' teaching methods and teaching organization. EA became the acceptable alternative to CAH by the late 1960s and got rapid development in the 1970s.

5. Interlanguage

The credibility of Error Analysis has been damaged seriously in the 1970s because of its obvious drawbacks. With the exploration of new theories, the emphasis of SLA is placed not on the relationship between L1 and L2 but on the learner language. Learner language can provide the researcher with insights into the process of acquisition. For many researchers, although not all, learner language constitutes the most important source of information about how learners learn L2, and hence, the term interlanguage is first used by the American linguist Selinker (1972).

\section{B. Recent Studies of Negative Transfer in College Students Writings}

Negative transfer from the linguistic aspect can be divided into four types: lexical negative transfer, semantic negative transfer, syntactic negative transfer and Chinglish expression. In the following subchapters, the present writer intends to analyze the errorscaused by negative transfer from the four different angels.

\section{Negative transfer in lexis}

English has a developed pronoun system, compromising personal pronouns, possessive pronouns, reflexive pronouns, reciprocal pronouns, demonstrative pronouns, interrogative pronouns, relative pronouns and indefinite pronouns (Zhang, 1997). Most English sentences are composed of subject and predicate, and the latter is more important which decides sentence patterns. Additionally, predicates are indispensable in English and are composed of verbs.

2. Negative transfer in syntax

English and Chinese belong to different language families, so they differ widely in grammatical systems. The rules of grammar, which are used for ordering and connecting words, are called syntax. Nowadays people have already widely believed that to realize effective communication, sentences are key linguistic unit and they can be infinite in numbers among every language. Transfer at the level of syntax is mainly attributed to the syntactic differences and partially to the semantic differences between the native language and the target language. The word order of a certain element is determined by three factors: grammatical factor, rhetorical factor and idiomatic factor. Most English sentences are composed of subject and predicate, and the latter is more important which decides sentence patterns.

\footnotetext{
3. Negative transfer in discourse
} 
A text is a complete linguistic unit to discuss a topic. The term "discourse" is also used by some linguists to refer to this unit who state a text should meet seven standards of textuality, namely, cohesion, coherence, intentionality, acceptability, informativity, situationality and inter-textuality. Halliday divides cohesion into five types: reference, substitution, ellipsis, conjunction and lexical cohesion (Liu, 1999).

4. Chinglish Expression

Ge (1984) is the first scholar who proposes the terms "Chinglish" and "China English" in his essay On Chinese to English Translation. Since Ge, many scholars have also illustrated their points of view. Yang (2000) and many other scholars think the existence of Chinglish is objective, and is an unavoidable language phenomenon. They also point out Chinglish is a typical example which, in a way, manifests the influence of Chinese into learning English as some sentences are translated into English following word to word order. Because of the interference and influence of their mother tongue, Chinglish comes into being when Chinese draw upon Chinese rules and structures unconsciously into English language. Common errors of Chinglish are generally divided into four levels which touch on pragmatics, lexicology, syntactics and pronunciation.

It is well known that different cultures have their own vocabularies, forms as well as ways of thinking, which can be easily seen from a native people's writing. Based on the above literature review, the study is intended to make a further investigation on Chinese negative transfer in college students' writings from the perspective of culture.

\section{Negative Transfer of Different Culture in Students’'Writings}

It is well known that different cultural signs like words and expressions, sentence patterns and ways of thinking can be easily observed in writing products of foreign language learners. In this chapter the author is going to detect the errors in their writings from the narrow sense of culture, which includes idioms, cultural terms and expressions. As the author explained at the very beginning of this chapter, the study is conducted from both linguistic and cultural perspectives, it is also reasonable to say that the study is carried out according to the understanding of the concept of culture, from narrow and broad sense respectively. Therefore, in this chapter the main task for the author is to detect the negative transfer under the perspective of narrow sense of culture, that is, idioms, cultural terms and conventions in expression.

\section{A. Negative Transfer in Idioms}

Culture can be regarded as a system and collection of shared values, performances and handmade crafts that members of a community employed to get along with others and to deal with their daily lives since languages are inseparable with their cultures and every nation has its unique culture, it is necessary for students to learn the target culture before learning its language. Languages of different nations varied in the light of the meaning of word, not just at the level of denotation but connotation as well. The definition of denotation comes down to what dictionary writes; to be more simply, it usually indicates the literal meaning of words. When we look up a word, for example "desk", in a dictionary, we would find that the denotative meaning of it is defined as "a piece of furniture that is like a table and often has drawers." Connotation directs at associative meanings or affective imaginations of the word. For a word, its denotative meanings coexist with its connotative meanings. Here are some examples in students' compositions.

a. China will become a flying dragon in the near future.

b. When I was in high school, I felt like a dog.

c. Individualism is not allowed in class, because it is bad for the creation for a harmonious atmosphere.

There are three typical examples about the misunderstanding of the connotation of English words. Dragon is a kind of creature which usually represented as breathing fire and Master's Thesis "dog" is always seen as a positive word. The third example is about the understanding of the word "individualism". Because of the social background and historical development, Chinese students always think the negative influence of "individualism", as a result the word negative one. But in English, the words stand for their values and human nature, it is a neutral word. Apparently, this sentence is going extreme in meanings.

Idioms, having gone through a quite long period in history, can best represent the similarities and differences between two nations. Although they are not as important as other language elements in forming the main part of a unique language, it is still irreplaceable. The connotations of idioms in different languages are not the same, even widely divergent. Chinese students try to translate Chinese idioms into English while writing, sometimes they could achieve their goal, but in most times, they made stupid mistakes.

a. When I walk by the side of the river, I found an old man sitting there. I come to the front and say hello, only to find that he is a professor in my university who I admire the most. It is when the Tai mountain is in front of you, but I could not recognize it.

b. My English teacher always says, don't display ax before Luban.

\section{B. Negative Transfer in English Terms and Expressions}

The subcategory of English terms can be detected from many aspects, such as science \& technique terms, political terms, religious terms, linguistic terms, legal terms, trade terms and so forth. In some cases, Chinese and English terms can be translated to each other, while some others are unable to be translated without losing part of the meanings. 
Chinese students ought to pay more attention to use English terms and expressions in case of committing errors. The last thing for them to do is creating words or phrases according to Chinese language habits. Here are some examples about wrong use of terms and expressions:

a. "This caricature writing needs to be finished before noon", My teacher said.

b. If a student just learn some knowledge and make an achievement in his field, he may not succeed in his work, because he has not the moralities like cooperation.

The two are the examples of terms which can be analyzed one by one. The italic part of he first sentence should be corrected like "cartoon writing" although it is passable in meaning. The word "cooperation" is inappropriate in second sentence, which could be replaced by "cooperative consciousness".

\section{Sources of Negative Transfer From Cultural Aspect}

In the previous subchapter, the author has analyzed the writings from cultural aspect. However, the job has not finished, yet the most important thing is to trace the sources of negative transfers, which is the main task of this chapter.

\section{A. Thinking Mode}

Values are valuative components of our belief and attitude systems. Valuative qualities include usefulness, goodness, aesthetics, ability to satisfy needs, and ability to produce pleasure. Values are broad, abstract concepts which provide the foundation of a person's living style, and they are reflected in many aspects. Values accepted and performed in a society generally act as norms in help its members to tell what is good and what is bad, what is beauty and what is ugliness, what is right and what is wrong, and finally what is true and what is false. Value ranges narrowly from community to community and widely from country to country, resulting in easily getting it wrong under international communicative situations, especially between western and eastern countries.

As for Chinese and English values, there is no good or bad, right or wrong, the difference of the two mostly lies in the thinking mode. Having experiencing a long superstitious period in history and being controlled by the Confucianism, Chinese people from now are still worship the authority and emphasize the self-control. Unlike the Chinese way, western people stress the individualism as well as pursue the freedom. Meanwhile, many other differences of Chinese and western thinking mode can be detected here for the purpose of clarifying the reason of the negative transfer clarifying the reason of the negative transfer.

In ancient times, Chinese trusted in the viewpoint of unity between human beings and the nature while western people held the opinion of multiformity. These different outlooks of the world lay the foundation of two different thinking patterns between westerners and easterners: Chinese people form their thinking patterns of Entirety and Synthesis; on the contrary, the westerners used to think logically and rationally. In other words, the Chinese formed their way of thinking from big to small or from whole to part, and ultimately reach a balance state, and the Chinese stresses the idea of "Parataxis" in discourse construction. The connection in the discourse is not so closely as in the English. But the westerners consider the thing from a part to the whole, and the analytic and linear way is the feature of western thinking pattern. Owing to the difference between Chinese and English thinking mode, it is unquestionable that Chinese students are always interfered by their mother tongue in organizing the structure of a passage.

Take a paragraph for example.

As far as I'm concerned, to solve this problem is very important. From the parents' aspect, they should realize that what the society needs is a perfect student, and the student should do well in every aspect, not just in study. The problem is serious, and both the parents and children should strive to solve this problem. So the parents should develop every aspect of their children and also encourage them to form a good habit which can enhance their living skills. If it does, I'm sure that the students will have a wonderful future and successful life.

Regardless of the grammar, the structure of this paragraph seems really odd. As a matter of fact, the aim of this paragraph is to provide effective ways to solve the problem; however, owing to the influence of the mother tongue, which is the spiral form in structure, the student failed to highlight the key points of this paragraph. In addition, the excessive use of the modal verb is another feature of Chinese students.

\section{B. Aesthetic Perception}

Although the nature of human beings and their sense mechanism work much the same in Chinese and westerners, the difference in their historical development, their life experience even their geographical location provide people of difference cultures with different insight into the world. The same is true in the case of the aesthetic views in the eyes of easterners and westerners. Actually, we can easily see a great deal of striking differences of aesthetic views between Confucianism and the western philosophers.

Compared to the Chinese, sterners are later discoverers and admirers of natural beauty. In addition, their relationship with nature used to be more of one of conflict, conquest and disharmony. In contrast, the Chinese were earlier perceivers of natural beauty, who placed a high value on getting close to nature, harmony with nature and the unity of man with nature. As far as aesthetic forms are concerned, westerners are satisfied with objective representation and description of nature and stop at formal similarity because they seem to prefer a distant, objective and passive look at nature so as to analyze and "dissect" it. On the other hand, the Chinese, being habitually introspective, are sensitive 
static observers of nature and keen seekers of spiritual harmony with nature. As far as their art forms are concerned, the Chinese are better at subjective description and expression. As a result, the western perspective of natural beauty is more philosophical and rational and has a solid theoretical basis; on the other hand, the Chinese aesthetic theories are more empirical and practical and are fully expressed with greater detail.

Aesthetic ideas, for example arts for art's sake, revealed in western cultures, have never arisen in Confucianism. On the other hand, Confucianism believes in teaching as well as instrumental effects of art works, and upholds ethical and political impacts showed in aesthetic crafts.

And also Chinese people consider the Analects of Confucius, Poetry of Tang and Song Dynasties as beauties. Westerners, however, find them difficult to understand, needless to say, the appreciation. Therefore, under the influence of Chinese poetry, Chinese students prefer to use the simple paralleled sentences while writing, which sometimes are odd for native speakers.

For example, and everything will lead to a happy and harmonious society. And we will live a happy life forever. And our country will become more and more powerful.

Influenced by Chinese aesthetic perception, students prefer to put several simple sentences together in their compositions. They consider these sentences as parataxis sentences. The example above is a typical parataxis sentence if translated in Chinese. And the relations among the three sentences are progressiveness. However, it is odd and inappropriate for native speakers, let alone enhancing the aesthetic feelings of a whole passage.

\section{Religious Belief}

Religion, being a kind of national culture, implies the angles of different thoughts development. It is reflected into people's everyday life and accordingly leads to cultural diversities.

As is known to all, China is a multi-national country and there exists different religions among which, however, Buddhism is the most influential one on Chinese culture. After being brought into China, Buddhism had and has affected Chinese culture in every regard and deeply accelerated the flourishing of Chinese literature. Enormous phrases, expressions, and idioms dating back from Buddhism are the exact manifestations beyond its influence. When the author looked up the dictionary and find many Chinese idioms are associated with Buddhism. Based on an authentic calculation the total number of Chinese idioms related to Buddhism come up to over two hundred. Such as "xian shen shuo fa (现身说法)," in English it means “to make a personal example as an effective means of convincing others," “fang xia tu dao, li di cheng fo (放下屠刀，立地成佛)” which refers to “A butcher turns into a Buddha at the time he or she drops his or her knife—-the misguided people get salvation provided they stop evil acts." "jiu ren yi ming sheng zao qi ji fu tu (救人一命胜造七级浮屠)" which indicates “saving a human is superior than constructing a seven-storeyed pagoda." Some expressions in these idioms like “shen (身)”, “fa (法)” “chu jia (出家)”, “cheng fo (成佛)” come from certain ceremonies in Chinese Buddhism.

Moreover, most ordinary Chinese possess a belief that Heaven be the supreme organ of the authority. They have a strong feeling of dependence on the Heaven: everything is controlled and arranged by the Heaven. based upon this, the idioms “mou shi zai ren, cheng shi zai tian (谋事在人，成事在天)” which means humans propose a plan but Heaven decides whether the plan would be successful or not, and “sheng si you ming, fu gui zai tian (生死由命, 富贵在 天)”which implies a person's life as well as death are issued by the fate, and rank and riches ordered by Heaven, takes their shape.

In western countries most people are Christians; therefore they worship that the whole creatures on the earth were brought about by God; hence the entire world is settled and arranged under God's willpower. All kinds of Christian views were written in a book called Bible, inside which numerous idioms were recorded because people who trust in Christianity all read the Bible. Consequently, lots of idioms swarm into people's daily lives and emerged into their colloquial expressions and as time passing by, some gradually become mottoes, for example, "God helps those who help themselves."

Here is a famous saying excerpted from Bible, i.e. the Revelation in New Testament (1998) in chapter eleven which could draw a clear picture of their belief toward the God in western countries: "Hallelujah! For the Lord our God the Almighty reigns. The kingdom of the world has become the kingdom of our Lord and of his Messiah, and he will reign forever and ever". Just as what the word Heaven in our Chinese culture denotes, everyone in western knows so much about the meaning of the word God that they use the word frequently in their casual conversation, for example, they would say "Oh, my God", "Thank God", "God bless me", for the reason that westerners think God stands for good and he is able to help them when they get into a jam.

In students' compositions many errors were made because of the difference of religion. Such as:

c. It is the Heaven who masters the fate.( the God)

From the examples, we can see, Chinese students are very much inclined to make mistakes while writing because of the different religious beliefs. Being innocent to the target culture's religion they will misunderstand the superficial sense of a passage or even go to wrong directions in grasping the original meaning of a sentence. Therefore, the impartation of knowledge in this area is of crucial importance.

\section{How to AVOID Negative TransFer IN WRITINGS}


In this chapter the main efforts will be on the introduction of a new effective teaching mode which could help the students a lot in avoiding most of negative transfers efficiently.

As discussed previously, culture should be introduced in class. However, as to new teaching mode, which suits the development of today's society, the introduction of culture is insufficient. There should be other relative factors such as focusing on the students and teaching grammar in class. According to the author's experience, many college English teachers attach less importance to the students. They form the way of teaching as teachers' monologue. Many factors such as course arrangement or the plan of textbooks induced this phenomenon. Students should take the priority in class regardless the limits of time or unreasonableness of textbooks. Teachers should encourage their students to be active in class and to talk with foreigners bravely.

\section{A. From the Teachers'Role}

This research will help a lot from both the teachers' and students' aspects and it enables the teacher to find a rather efficient way to teach how to write clearly and natively. As a result, the following subchapters are the duties which teachers should do in a successful writing teaching class.

1) Making contrastive analyses

All of us know that most negative transfers in Chinese students' writings are due to the culture differences. Therefore, it is extremely important for English teachers to analyze the differences between native and target language in FLT class. First, they should make a careful study on the differences between English and Chinese, including language itself and culture. Then based on the study, teachers should add intercultural information in class to help the students think in a native way. The more they know the differences, the better they understand the language. Gradually, the students form the habits of thinking in a more native way which will reflect in their language skills, writing in particular. At last, Students will find their interest in English learning process, and become an active learner.

2) Creating western culture atmosphere

Creating a suitable atmosphere for students is also important. Teachers are obliged to create as authentic western culture atmosphere as possible for the aim of making students plunge into classroom situations and learn to first off speak and then utilize English within various contexts. In terms of creating a proper and successful cultural environment, teachers are advised to speak English before, during and after English classes, screen clips of films or conducting English role-plays. These are efficient teaching methods in helping students become interest and even boost their target language abilities, particularly those cultural ones. English teachers could instruct students to imitate movie clips or daily monologues and act them out before the class, like greetings, asking for directions, making reservations through cell phones. Amid the courses of involving in these activities, students experience different cultural appeals; therefore there is no doubt at all that their understanding in target language rose day after day.

3) Utilizing the movies

As we all know, movies are always rich in language use and cultural background. Students have a strong tendency to memorize the characters, the plot and even words in the movie. From the movie students can learn how those people communicate in real life and they begin to imitate. Therefore, if teachers can make good and proper use of movies in class, the language proficiency of their students will be enhanced unconsciously. Nowadays, foreign movies or TV series are easily available, the utilization of them seems quite important.

\section{B. From the Students'Role}

In the last subchapter the author has explained the pedagogical implications from teachers' role only, and we know that teachers play an important role in writing teaching process. Nevertheless, we should not forget another crucial factor in writing, i.e. the role of students.

1) The accumulation of vocabulary

It is a truth that the biggest obstacle in writing is the weak basis of vocabulary, thus solidifying the basis is of capital importance. One can choose words properly in a certain context if he has a solid word foundation. However, in addition to the quantity of acquired vocabulary, here comes another problem. Chinese EFL learners are incline to pay attention to equivalent words and expressions between Chinese and English, leading to their translation works characterizing words to words. Based on this, it is worthwhile for Chinese ESL learners transforming their behaviors of mastering English words and phrases, i.e. the core of students' focus on vocabulary ought to be extended to concentrate not only on those meanings presented in their textbook glossary but also enlarging words' meanings from their basic meaning to various derived senses showed in certain contexts. On this ground, learners should put English words into specific language environment, to simply state, into a sentence, a paragraph or a scene.

2) The cultivation of language sense

The most important way of cultivating students' language sense is reading widely. Reading and writing are both language skills which assist mutually. In order to write coherently and logically, the students need to read an abundance of original works, from fictions to nonfictions, from serious works to children's books and from literature to philosophy. Teachers have the duty to recommend appropriate books to students and act as a supervisor for it is rather painful in the preliminary reading step. From a lot of reading, they can understand the target culture deeper and more specifically. Reading novels helps the students enter into another cultural atmosphere and get accustomed quickly. Though its gains cannot be seen in short period of time, it indeed helps them understand culture to a deep extent, and helps them 
understand the target nation's concept of value and their beliefs and realize the cultural differences. Thus we are all clear that reading can be a means to cultivate language sense, but still are there other ways, like watching foreign movies, scanning the foreign websites or listening to BBC or VOA.

3) The full use of initiatives

From the author's point a good writer is the one who makes full use of his initiatives, and grasps any chances to learn. Without doubt, teachers are perfect instructors in regard to teaching their home culture since they have immersed in and experienced their national cultural environment from the very time they born. Many students confirmed that it is easier for them to get aware of and have a deeper impression with British and American cultures in oral classes which are given by native language teachers than in classes delivered by Chinese English teachers. Students expressed that by communicating with their foreign language teachers front to front, they are capable of observing and perceiving cultural differences between Chinese culture and western culture, not to mention getting personal opinions on some cultural stuff, which are beneficial to their language learning.

As regard English acquisition in China, Chinese English teachers are believed to serve as a guider to guide students to switch their thinking model and follow what natives do concerning language learning. They can help students familiarize western cultures and avoid using Chinese thinking to speak and write English as much as possible so that we can become accustomed to western style of thinking and finally achieve a marvelous progress. Take this as an example, when an English teacher explains western festivals, which are parts of Western culture and therefore a little difficult to be understood for Chinese students, to his or her students, such as Thanks Giving Day, Halloween, and Hanukkah etc., his or her counseling would contribute students to understand them more quickly and on a much wider scale.

Cultural discussion is a good way to understand culture step by step. It is widely used in Western countries. For Chinese students, attending any kind of cultural discussion will help them a lot. Through such kind of discussion, they know more details about target nations. Of course, there are some other ways that are conducive to cultivate our socio-cultural abilities, as through cultural lectures, cultural excursions, or through English corners, etc. Such activities can give the students information on Western culture, helping them learn Western culture much better.

\section{CONCLUSION}

Language and culture are closely related to each other. On the one hand, Language is the vehicle of culture as well as a means of communication. Lacking of languages makes it impossible to spread any kind of culture because language is the carrier of a country's values and culture. In contrast, languages become difficult to understand, nevertheless to acquire, if there does not exist a concrete cultural context to consult to. As a result, a deep study of the relationship between language and culture is not only necessary but also urgent in language teaching and learning. That is to say, teachers should teach English language as well as its culture in their classroom and most teachers do teach in this way. However, the result seems unpleasant since there is no effective way to integrate both language and culture in foreign language teaching, especially in English writing teaching.

In China, English writing is considered the most difficult skill to acquire, because both teachers and students are unable to find an effective way to enhance this kind of skill. But the importance of writing has never been underestimated during the learning or teaching process. Since English was introduced in China as a foreign language many researchers and linguists have endeavored themselves into this task, they try to find a possible way to improve students' learning proficiency. Cultural negative transfer is one common phenomenon in students' writings. Therefore, both teachers and students should take some measures to avoid such language negative transfer.

\section{REFERENCES}

[1] Eckman, F. (1977). Markedness and the contrastive analysis hypothesis. Language Learning, 27(2), 315-330.

[2] Ellis, R. (2009). The study of Second Language Acquisition. Shang Hai: Shang Hai Foreign Language Education Press.

[3] James, C. (2005). Contrastive Analysis. Qing Dao: Qingdao Publishing House.

[4] James, C. (2001). Errors in Language Learning and Use: Exploring Error Analysis. Bei Jing: Foreign Language Teaching and Research Press.

[5] Kellerman, E. \& Sharwood Smith, M Alonso, R. A. (2016). Crosslinguistic Influence in Second Language Acquistion. Toronto: Multilingual Maters.

[6] Kluckhohn, C. (2017). Mirror for Man-The Relation of the Anthropology to Modern Life. London: Routledge.

[7] Lado, R. (1957). Linguistics across Cultures: Applied Linguistics for Language teachers. Michigan: University of Michigan.

[8] Odlin, T. (2001). Language Transfer-Cross-Linguistic Influence in Language Learning. Shang Hai: Shang Hai Foreign Language Education Press.

[9] Richards, J. (2000). Longman Dictionary of Language Teaching and Applied Linguistics. Bei Jing: Foreign Language Teaching and Research Press.

[10] Sajavaara, K. (1986). Transfer and Second Language Speech Process. New York: Pergamon Press.

[11] Selinker, L. (1972). Interlanguage. International Review of Applied Linguistics in Language Teaching, 10(3), 21-30.

[12] Wei, Y. Q. \& Li, J. (1998). New Testament. Tian Jin: Tian Jin Peoples Publishing House. 
Lin Bai was born in Lvliang, China in 1991. She is a postgraduate student in the School of Foreign Languages at Shanxi Normal University in China. She received her B.A. degree in English from Modern College of Science and Arts, Shanxi Normal University in 2014.

Jie Qin was born in Gaoping, China in 1975. He received his Ph.D. degree from Shanghai Normal University. He is currently associate professor and master's supervisor in Shanxi Normal University. His research interests include theories and practices in English course and language teaching and psycholinguistics. Doctor Qin has took part in a series of research and teaching activities during which he published several articles; he was also responsible for at least 9 scientific research project. 